\title{
Práticas de governança eletrônica e eficiência na utilização das receitas: uma análise nos estados brasileiros
}

\author{
Ilse Maria Beuren \\ Universidade Federal do Paraná \\ Geovanne Dias de Moura \\ Universidade Regional de Blumenau \\ Nilton Roberto Kloeppel \\ Universidade Regional de Blumenau
}

\begin{abstract}
A pesquisa objetiva analisar as práticas de governança eletrônica dos estados brasileiros e sua correlação com a eficiência na utilização das receitas. Pesquisa descritiva foi conduzida por meio de análise documental e abordagem quantitativa. A amostra intencional e não probabilística compreendeu os 26 estados brasileiros. O Distrito Federal foi excluído da amostra devido à indisponibilidade de dados para a pesquisa. Na análise dos dados utilizaram-se medidas de estatísticas descritivas, análise de correlação de Pearson e cálculo da eficiência com o software DEA-Solver. Os resultados evidenciam que os estados com melhores práticas de governança eletrônica localizam-se na região Sudeste, seguidos dos da região Sul. O índice médio geral de governança foi de 58\%, muito distante de 100\%. Em relação à eficiência no uso das receitas, os cálculos pelo DEA mostram que todos os estados das regiões Sul e Sudeste apresentam score1, considerados eficientes em relação aos demais. A região Norte apresentou a menor média $(0,94)$ de eficiência. Pelos cálculos do DEA, 17 estados atingiram score 1 , indicando que a maioria dos estados brasileiros é eficiente na utilização das receitas. Constatou-se ainda que os estados com melhores práticas de governança eletrônica são os que apresentam maior eficiência na utilização das receitas.
\end{abstract}

Palavras-chave: governança eletrônica; eficiência; receitas; estados brasileiros.

Prácticas de gobierno electrónico y el uso eficiente de los ingresos: un análisis en los estados brasileños

La investigación tiene como objetivo analizar las prácticas de gobierno electrónico en los estados brasileños y su correlación con el uso eficiente de los ingresos. La investigación descriptiva se realizó mediante el análisis de documentos y un enfoque cuantitativo. La muestra no probabilística intencional e-compuesto por los 26 estados brasileños. El Distrito Federal fue excluido de la muestra debido

Artigo recebido em 27 jan. 2012 e aceito em 23 nov. 2012. 
a la falta de disponibilidad de datos para la investigación. Al analizar los datos se utilizaron medidas de estadística descriptiva, análisis de correlación de Pearson y la eficiencia de cálculo con el software DEA-Solver. Los resultados muestran que los Estados con mejores prácticas de gobierno electrónico se encuentran en el Sureste, seguida de la región del Sur. La gobernanza global promedio fue de 58\%, lejos del 100\%. En relación con la eficiencia en el uso de los ingresos, los cálculos de la DEA muestran que todos los estados del Sur y Sureste tiene puntuación 1, considerados eficientes en comparación con los demás. La región Norte tuvo el promedio más bajo $(0,94)$ de eficiencia. En los cálculos de la DEA, 17 estados alcanzaron puntuación de 1, lo que indica que la mayoría de los estados brasileños es eficiente en el uso de los ingresos. También se encontró que los estados con mejores prácticas de gobierno electrónico son las que tienen una mayor eficiencia en el uso de los ingresos.

Palabras clave: gobierno electrónico; eficiencia; ingresos; estados brasileños.

Electronic governance practices and efficiency in the use of the revenue: an analysis on the Brazilian states

The goal of this research is to analyze the electronic governance practices of the Brazilian states and their correlation with the efficient in the use of the revenue. A descriptive research was conducted through document analysis and quantitative approach. The intentional and non-probabilistic sample comprised the26Brazilian states. The Federal District was excluded from the sample due to unavailability of data for the research. In the data analysis measures of descriptive statistics, Pearson's correlation analysis and calculation of efficiency with DEA-Solver software were used. The results show that the states with the best practices of electronic governance are located in the Southeast, followed by the ones in the South Region. The overall average index of governance was 58\%, very far from $100 \%$. Regarding the efficiency in the use of the revenue, DEA calculations show that all states in the South and Southeast have score 1, considered efficient in relation to the others. The North Region had the lowest efficiency average (0.94). According to DEA calculations, 17 states reached the score 1, indicating that the majority of the Brazilian states is efficient in the use of the revenue. It was also observed that the states with best practices of electronic governance are the ones with more efficient use of the revenue.

KEY WORDs: electronic governance; efficiency; revenue; Brazilian states.

\section{Introdução}

As mudanças, sociais, econômicas e políticas em âmbito mundial, e também a consolidação da democracia no Brasil, tornaram os cidadãos mais exigentes com a gestão em si das organizações e a transparência dos atos administrativos. Esta postura passou a exigir das entidades públicas e privadas novos e inovadores modelos de gestão, assim como novos instrumentos e formas de administração (Soares Júnior e Santos, 2007).

No Brasil, as reformas na administração pública, iniciadas principalmente em maio de 2000, com a aprovação da Lei Complementar no 101, Lei de Responsabilidade Fiscal (LRF), visam maior transparência, junto à sociedade, dos fatos contábeis, econômicos e administrativos das entidades públicas. Em maio de 2009 foi aprovada a Lei Complementar no 131, que acrescentou dispositivos à Lei Complementar no 101/00, objetivando que o gestor público 
disponibilize, em tempo real, informações detalhadas sobre a execução orçamentária e financeira da União, dos estados, do Distrito Federal e dos municípios.

Esses fatores exigem dos governos maior abertura e interação com a sociedade civil. Governos do mundo inteiro estão buscando aproveitar potencialidades oferecidas pelas tecnologias da informação para criar novas dimensões de progresso econômico e social (OkotUma, 2000; Potnis, 2010). Para as organizações públicas, segundo Araújo e Laia (2004), as tecnologias da informação podem representar a possibilidade de um novo foco na prestação dos serviços públicos.

A utilização de tecnologias da informação e da internet, visando aumentar a eficiência e transparência da administração pública, tem sido denominada governo eletrônico (OkotUma, 2000; Riecken, 2008; Janowski, Pardo e Davies, 2012). Entre os principais instrumentos do governo eletrônico, conforme descrevem Araújo e Laia (2004), encontram-se os portais de governos na internet, onde informações e serviços públicos podem ser acessados a qualquer tempo e local (Araújo e Laia, 2004; Bhuiyan, 2011).

O governo eletrônico, segundo Ribeiro (2008:1), "tem sido visto como um promotor da transparência, pois permite que o cidadão acesse com maior facilidade as informações referentes à administração pública e propicia um ambiente que pode ser utilizado para a interação entre Governo e sociedade". No entanto, de acordo com Evans e Yen (2006), não se limita apenas em melhorar as relações entre governo e sociedade, pois se trata de um conjunto amplo de ações que também auxilia internamente, como na obtenção de dados para melhorar a tomada de decisões, no controle de gastos e para maior eficiência na aplicação de recursos.

O governo eletrônico faz parte da governança eletrônica, que é um conjunto de ações que visa, principalmente, proporcionar maior acesso à informação e conhecimento sobre o processo político (Holzer e Kim, 2005). Todavia, tais ações não envolvem apenas administração de tecnologia, mas também o gerenciamento de mudança organizacional, pois a todo momento surgem novas necessidades que exigem a criação de novos serviços, distribuição de informações e comunicação, por exemplo, com cidadãos e parceiros de negócios (Rezende e Frey, 2005).

A governança eletrônica é consequência de um cenário cada vez mais desenvolvido, de crescente sofisticação e que exige um conjunto de ações que engloba novos estilos de liderança, novas alternativas de debater e decidir estratégias, novas formas de acesso aos serviços, novas transações de negócios, novas formas de acesso à educação, novas maneiras de ouvir a comunidade e novas formas de organização e prestação de informação aos cidadãos (OkotUma, 2000; Potnis, 2010; Janowski, Pardo e Davies, 2012).

As práticas de governança eletrônica têm sido objeto de pesquisas para identificar fatores que expliquem sua utilização. Huther e Shah (1999), por exemplo, relacionaram a utilização de práticas de governança eletrônica com o Produto Interno Bruto (PIB), Índice de Desenvolvimento Humano (IDH) e tamanho, em uma amostra de 80 países de diversos continentes, e encontraram correlações positivas e significativas entre as variáveis para inúmeros países. No Brasil, em estudo realizado por Mello (2009) foi encontrada correlação de $73 \%$ e $40 \%$ 
entre os índices de governança eletrônica e o PIB e o IDH, respectivamente, em uma amostra composta por estados brasileiros. Moura e colaboradores (2011) encontraram correlação positiva entre PIB (62\%), IDH (37\%) e tamanho (52\%) em municípios catarinenses.

Percebe-se que o PIB e o IDH são variáveis que contribuem para explicar a utilização de práticas de governança eletrônica, ou seja, municípios com melhores condições socioeconômicas mostraram-se mais aderentes às práticas de governança eletrônica. Assim, uma hipótese seria que uma melhoria nas condições socioeconômicas das regiões proporcionaria aumento na utilização das práticas de governança eletrônica, mas para isso é necessário que o governo utilize seus recursos de maneira eficiente.

Com base no exposto elaborou-se a seguinte questão de pesquisa: os estados brasileiros que possuem maior eficiência na utilização das receitas apresentam melhores práticas de governança eletrônica? Assim, o objetivo da pesquisa consiste em analisar as práticas de governança eletrônica dos estados brasileiros e sua correlação com a eficiência na utilização das receitas.

A relevância da pesquisa está no fato de buscar contribuir para a avaliação das práticas de governança eletrônica em governos estaduais. Portanto, a pesquisa justifica-se por suscitar discussões sobre elementos que influenciam e são influenciados na implantação de tais práticas. Desta maneira, os gestores públicos poderão analisar os pontos a serem melhorados, no sentido de fornecer um atendimento melhor à população.

O artigo está estruturado em sete seções, iniciando com essa introdução. Depois, aborda conceitos sobre governança eletrônica, seguido de receita pública e estudos anteriores sobre o tema. A seção cinco apresenta os aspectos metodológicos utilizados para o desenvolvimento da pesquisa, seguida da apresentação e análise dos dados. Por fim, apresentam-se as considerações finais da pesquisa.

\section{Governança eletrônica}

A ampliação do uso dos computadores e a evolução dos meios de comunicação, segundo Mello (2009), proporcionam novas formas para os modelos de relacionamento Estado-sociedade, que se tornam a cada dia mais baseados em novas tecnologias de informação e comunicação. Esse conjunto de tecnologias (informação e comunicação) apresenta potencial, de acordo com Mello (2009), para construir uma nova relação entre governo e cidadão, em virtude da possibilidade de proporcionar uma administração pública mais eficiente, democrática e transparente.

É nesse contexto que se insere a governança eletrônica, cujo foco é a utilização das tecnologias de informação na busca de uma melhor atuação social (Mello, 2009; Potnis, 2010; Janowski, Pardo e Davies, 2012). A governança eletrônica, conforme Okot-Uma (2000), não é um conceito que entrou recentemente em uso regular nas ciências políticas e na administração pública. Ele aparece ao lado de conceitos e termos como democracia, sociedade civil, par- 
ticipação popular, direitos humanos e sociais, e que na última década tem sido intimamente associado à reforma do setor público.

A governança eletrônica tem contribuído para uma melhor gestão profissional no setor público, proporcionando respostas para as questões ligadas à capacidade dos governos de prover infraestrutura e também tem sido fundamental na gestão dos recursos de tecnologia da informação relativos à oferta de serviços públicos e prestação de informações eficientes (Riecken, 2008; Janowski, Pardo e Davies, 2012).

Prestar informações de modo rápido e eficiente é algo fundamental para aproximar os cidadãos da gestão urbana, de acordo com Rezende e Frey (2005). No entanto, sua disseminação e compartilhamento exigem a utilização de recursos da tecnologia da informação. Rezende e Abreu (2003) definem a tecnologia da informação como um conjunto de recursos tecnológicos e computacionais que facilitam a geração e o uso da informação.

A introdução das tecnologias da informação em organizações governamentais, incluindo a criação de redes de informação do governo, segundo Janowski, Pardo e Davies (2012), tem contribuído para a melhoria de processos internos do governo e também para fortalecer as relações entre o governo e os cidadãos, empresas e outros atores não estatais. No entanto, Mello (2009) alerta que sozinha a tecnologia da informação não faz política ou revoluciona costumes e éticas. Todavia, com o desenvolvimento das tecnologias da informação, “(...) a governança eletrônica aparece como uma tendência emergente para reinventar o funcionamento do governo, especialmente na oferta de serviços públicos e participação cidadã na gestão, de maneira on-line" (Mello, 2009:39).

De acordo com Holzer e Kim (2005), a governança eletrônica engloba o governo eletrônico, que está relacionado com a prestação de serviços públicos, e a democracia eletrônica, que trata da participação cidadã. Os autores mencionam ainda que o governo eletrônico e a democracia eletrônica são representados por cinco subgrupos de práticas: conteúdo, serviços, participação cidadã, privacidade e segurança e usabilidade.

Para Holzer e Kim (2005), a governança eletrônica engloba o governo eletrônico e a democracia eletrônica. O governo eletrônico utiliza-se das tecnologias da informação para melhorar a prestação de serviços aos cidadãos, além de envolver ações internas, tais como obtenção de dados que auxiliam na tomada de decisão e possibilitam ao governo comprar produtos, pagar faturas e realizar negócios de maneira mais eficiente (Holzer e Kim, 2005; Evans e Yen, 2006; Georgescu, 2008; Mello, 2009). A democracia eletrônica abrange todas as formas e recursos de comunicação eletrônica que visam aproximar o Governo dos cidadãos (Okot-Uma, 2000).

Depreende-se que a governança eletrônica é um elemento inerente à gestão pública, seja por imposição legal ou exigência da sociedade civil. Não se admite mais que o poder público deixe de dar transparência de seus atos políticos, administrativos e econômicos. Como o poder público necessita de recursos advindos da sociedade para cumprir com o poder que lhe foi delegado, também os recursos econômicos (ingressos e saídas) constituem-se em alvo de transparência do governo eletrônico, que também é foco de análise desta pesquisa. 


\section{Receita pública}

Conforme o art. 9 da Lei no 4.320/64, a receita pública compreende o "tributo e a receita derivada instituída pelas entidades de direito público, compreendendo os impostos, as taxas e contribuições nos termos da constituição e das leis vigentes em matéria financeira". O referido instrumento legal ainda prevê que o ente público destina "o seu produto ao custeio de atividades gerais ou específicas exercidas por essas entidades".

Para Carvalho (2008), as receitas públicas são todos os recursos de caráter não devolutivo, instituídos e arrecadados pelo poder público em qualquer esfera governamental, com a finalidade de realizar gastos que atendam as necessidades ou demandas da sociedade. As receitas públicas podem ser classificadas, conforme sua natureza, em receita orçamentária ou extraorçamentária (Jund, 2006). A Receita Orçamentária, conforme Jund (2006:147), é a "fonte de recursos efetiva ou por mutação, pertencentes ao Estado, ou seja, não serão restituídos no futuro, previstos ou não na lei orçamentária e que será utilizada no financiamento de despesas públicas".

A Receita Extraorçamentária "é aquela que não integra o orçamento público, altera a composição do patrimônio financeiro, sem modificar a situação líquida da organização" (Quintana et al., 2011:44). Os autores comentam ainda que este tipo de receita compreende "valores que o órgão público arrecada, mas não lhe pertencem, ficando assim de mero depositário de valores recebidos". São exemplos de Receitas Extraorçamentárias: fianças, depósitos de terceiros em garantia, salários não reclamados, retenções na fonte.

Economicamente as receitas públicas são classificadas, de acordo com a Lei no 4.320/64, em: Receitas Correntes e Receitas de Capital. As Receitas Correntes são "destinadas a atender despesas classificáveis em Despesas Correntes". De acordo com a Lei oㅡ 4.320/64, as receitas correntes compreendem as seguintes categorias de receita: tributária, de contribuições, patrimonial, agropecuária, industrial, de serviços, transferências correntes, outras receitas correntes (Brasil, 2011).

As Receitas de Capital têm a finalidade de atender às Despesas de Capital e o superavit do Orçamento Corrente (Brasil, 2013). Este tipo de receita é proveniente da realização de recursos financeiros oriundos de constituição de dívidas; da conversão, em espécie, de bens e direitos; dos recursos recebidos de outras pessoas de direito público ou privado. As Receitas de Capital, de acordo com a Lei no 4.320/64, compõem-se de: operações de crédito, alienação de bens, amortização de empréstimos, transferências de capital, outras receitas de capital, receitas de capital intraorçamentárias (Brasil, 2011).

Um ponto importante em relação às receitas públicas, que tem sido um tópico de discussão e despertado o interesse de inúmeros pesquisadores, é a eficiência na utilização de tais receitas (Narayan, 2005; Bucovetsky e Smart, 2006; Ferreira e Pitta, 2008; Brückner, 2012; Silva et al., 2012). Utilizar receitas públicas de maneira eficiente significa alocá-las de modo racional, planejado e com qualidade (Brückner, 2012; Silva et al., 2012).

A alocação eficiente das receitas, segundo Silva e colaboradores (2012), é um dos principais desafios dos gestores que precisam corresponder às expectativas de uma sociedade que, 
a cada dia, exige resultados que promovam a maximização do desenvolvimento econômico e social. Espera-se que melhor eficiência na alocação das receitas resulte em melhores índices socioeconômicos. Do ponto de vista do desenvolvimento socioeconômico, utilizam-se como principais medidas de análise o Índice de Desenvolvimento Humano (IDH) para análise do desenvolvimento social e o Produto Interno Bruto (PIB) para o desenvolvimento econômico.

Analisar a eficiência na utilização dos recursos públicos é algo extremamente importante e necessário, cujo objetivo principal é confrontar a adequação dessa utilização com os resultados alcançados. Depreende-se que o ambiente ideal é aquele em que ocorre uma melhor combinação entre a utilização das receitas públicas e os indicadores socioeconômicos.

\section{Estudos anteriores}

Ao buscar estudos anteriores publicados sobre o tema, identificaram-se pesquisas realizadas a fim de avaliar práticas de governança eletrônica em governos estaduais e municipais do Brasil. As pesquisas focalizaram essencialmente discussões sobre fatores que influenciam na implantação de tais práticas. Algumas dessas pesquisas, mais estreitamente ligadas à forma de abordagem do tema aqui pretendida, são apresentadas na sequência.

Silva e Correa (2006) objetivaram verificar a importância atribuída pelos governos municipais ao crescimento do empreendedorismo local por meio da governança eletrônica. Identificaram as informações relacionadas às políticas ou programas públicos que contribuíram à promoção do empreendedorismo nos municípios paranaenses que utilizaram sites como ferramenta da governança eletrônica municipal. Foram avaliados 372 portais de governos municipais, utilizando 34 indicadores considerados relevantes para a promoção do empreendedorismo, definidos a partir da revisão da literatura em livros, periódicos, artigos e anais de congressos científicos.

Os resultados apontaram que as iniciativas das prefeituras sobre esse aspecto ainda estavam em estágios iniciais. Mesmo os municípios com melhores resultados ainda apresentavam consideráveis pontos a se desenvolver. Dos 34 itens avaliados, o município que divulgou mais informações de auxílio e incentivo ao empreendedorismo foi o de Foz do Iguaçu, com 22 indicadores dos apontados. Entre os indicadores avaliados, o item mais apontado foi o que identifica se o município tem secretaria direcionada ao empreendedorismo, com 68 ocorrências, ou $17 \%$ dos municípios. O segundo item mais encontrado foi se a prefeitura disponibiliza em seu site informações referentes a editais e leilões eletrônicos, com 13,8\%. Dois indicadores não foram encontrados em nenhum dos sites municipais: divulgação de cursos de extensão e à distância voltados ao empreendedorismo; e disponibilização de acesso a revistas especializadas no assunto empreendedorismo.

Pinho (2008) investigou como governos em estados com níveis de desenvolvimento econômico e de posicionamentos ideológicos diferenciados montam e estruturam seus portais. O pressuposto do estudo era que governos politicamente mais avançados teriam maior interesse e preocupação em criar um portal mais informativo, transparente e participativo, 
para detectar os movimentos do governo eletrônico. Classificou o estudo como de casos múltiplos, de caráter exploratório.

Procedeu à investigação em dez portais governamentais, nove de governos estaduais: Bahia, Rio Grande do Sul, São Paulo, Minas Gerais, Rio de Janeiro, Paraná, Pernambuco, Santa Catarina e Goiás, e o portal do Distrito Federal (DF). Um modelo de análise foi elaborado a partir de experiências anteriores de diversos autores e instituições (Akutsu, 2002; Akutsu e Pinho, 2002; Moraes, 2004; Prado, 2004). Parte de uma primeira bateria de questões sobre a configuração do portal, com o objetivo de diagnosticar as condições de acesso a ele. Segundo o autor, se um portal pretende atingir o maior número possível de usuários, deve procurar ser de fácil entendimento e navegação, ainda mais considerando que muitos usuários não têm um nível educacional elevado. A segunda bateria de questões voltou-se para o grau de informação propiciado pelo portal, se ele mantém o usuário informado e se suas demandas de informações são atendidas de forma direta, fácil e objetiva. A terceira bateria trata da questão da transparência do portal, ou seja, da transparência do governo por meio do portal. A quarta bateria de questões abordou a participação popular, verificando como os governos constroem instrumentos que oportunizam essa participação, entendida como apresentação de sugestões, avaliação e acompanhamento de políticas públicas e de serviços públicos.

Constatou, de modo geral, que os portais apresentavam incorporações tecnológicas relevantes - ainda que com algumas ressalvas - e que havia tecnologia para disponibilizar informações (o que não podia ser subestimado), principalmente do setor financeiro e fiscal. Ainda assim, poderiam ser aprofundadas para melhorar o acesso dos cidadãos aos serviços. O que faltou, no entanto, segundo o autor, foi uma predisposição para implantação de procedimentos de accountability e participação. Em uma perspectiva otimista, o autor considerou que, apesar do quadro mostrado, o processo de governo eletrônico não falhou, pois ele estava em construção.

Mello (2009) objetivou identificar um conjunto de práticas de governança eletrônica para os estados brasileiros e Distrito Federal, mensurá-las e relacioná-las com seu desenvolvimento econômico e social. Realizou ampla pesquisa bibliográfica para a construção da plataforma teórica sobre a governança eletrônica, que permitiu identificar e organizar um conjunto de práticas que formaram o Índice de Governança Eletrônica dos Estados Brasileiros (Igeb). As práticas foram estruturadas em cinco subgrupos (conteúdo com 13 práticas; serviços com 16 práticas; participação cidadã com dez práticas; privacidade e segurança com oito práticas; e usabilidade e acessibilidade com 19 práticas). Considerou uma escala de 0 a 100, com pontuação igual entre os subgrupos de práticas e dentro de cada subgrupo igual entre as práticas. Os dados foram obtidos nos websites dos estados brasileiros e do Distrito Federal, no período de 18 a 28 de fevereiro de 2009.

Como proxy do desenvolvimento econômico utilizou PIB e PIB per capita do ano de 2006. Como proxy do desenvolvimento social utilizou o Coeficiente Gini da renda domiciliar per capita (Gini) do ano de 2007 e IDH do ano de 2005. Os resultados demonstraram que os estados de São Paulo, Rio Grande do Sul, Rio de Janeiro, Espírito Santo, Paraná, Bahia e Minas Gerais foram os com mais práticas implantadas. Já Mato Grosso do Sul, Rondônia, Amapá, Roraima, Maranhão, Goiás e Pernambuco possuíam menos práticas implantadas. Os resultados também evidenciaram que o Igeb teve correlação significativa com todos os índices 
de desenvolvimento utilizados. O autor concluiu que, de modo geral, os estados mais desenvolvidos (com maior PIB, maior IDH e menor Gini) eram aqueles mais bem classificados, ou seja, com maior número de práticas de governança eletrônica implantadas.

Moura e colaboradores (2011) analisaram as práticas de governança eletrônica de 57 municípios do estado de Santa Catarina com população acima de 20 mil habitantes e verificaram sua correlação com as variáveis PIB, IDH e tamanho. O estudo replicou, com algumas adaptações, a metodologia adotada por Mello (2009) quanto ao modelo de mensuração do grau de adoção de práticas de governança eletrônica.

Os resultados apontaram que, das cinco dimensões da métrica sobre as práticas de governança eletrônica, aquela que os municípios tiveram maior grau de adesão foi quanto à prestação de serviços, seguida pelas práticas de usabilidade e acessibilidade, conteúdo, participação cidadã e privacidade e segurança, nesta ordem respectivamente. Quanto ao índice de governança eletrônica geral dos municípios de Santa Catarina, os resultados indicaram que a adesão mínima de práticas foi igual a 13\%, o máximo de $76 \%$, enquanto a média dos municípios catarinenses foi igual a 50\%. O estudo concluiu que os municípios maiores e com melhores condições socioeconômicas representadas pelo IDH e PIB aderiram a um maior número de práticas de governança eletrônica.

Infere-se dos estudos apresentados que as práticas de governança eletrônica têm sido objeto de estudo de alguns pesquisadores que procuram, principalmente, identificar fatores que expliquem a utilização de tais práticas. Percebe-se que o PIB e o IDH são variáveis que contribuem para explicar a utilização de práticas de governança eletrônica. No entanto, no Brasil, pouca atenção tem sido dada em relação à análise de outros fatores, como a eficiência na utilização dos recursos públicos.

\section{Metodologia da pesquisa}

Para atender ao objetivo proposto no artigo, realizou-se pesquisa descritiva, conduzida por meio de análise documental e abordagem quantitativa. A amostra da pesquisa é do tipo intencional e não probabilística, compreendendo os 26 estados brasileiros. O Distrito Federal foi excluído da amostra devido à falta de dados disponíveis para realização da pesquisa.

O índice de governança eletrônica para cada estado foi calculado de acordo com itens do constructo da pesquisa de Mello (2009), elaborado a partir de ampla revisão da literatura. O índice apresenta cinco dimensões para avaliar as práticas de governança: práticas de conteúdo, práticas de serviços, práticas de participação cidadã, práticas de privacidade e segurança, práticas de usabilidade e acessibilidade.

Essa forma de avaliação das práticas de governança por meio de índices já foi utilizada em diversas pesquisas (Leal e Carvalhal-da-Silva, 2007; Lopes e Walker, 2008; Silveira et al., 2010; Moura et al., 2011). É uma forma interessante, principalmente pelo fato de os dados serem coletados manualmente em fontes públicas, não exigindo o envio de questionários, que pode resultar em baixa taxa de respondentes. Além disso, os dados são transparentes, de fácil replicação, uma vez que não requerem julgamentos subjetivos e são de fácil interpretação. O quadro 1 apresenta as referidas dimensões de governança eletrônica e as 65 perguntas que formam o índice. 


\section{Dimensões da governança eletrônica}

\begin{tabular}{|c|c|c|}
\hline \multicolumn{3}{|r|}{ Métrica para Construção do Índice de Governança Eletrônica dos Estados } \\
\hline \multicolumn{2}{|c|}{ Categ. } & Subcategorias \\
\hline \multirow{13}{*}{ 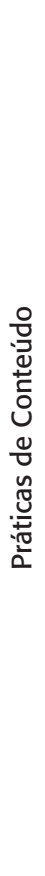 } & 1 & $\begin{array}{l}\text { Disponibiliza uma lista de links de órgãos internos e externos, a localização dos escritórios, agências, setores etc., } \\
\text { contato com horário de funcionamento, endereço, nomes etc. }\end{array}$ \\
\hline & 2 & Disponibiliza a agenda do gestor e das políticas da instituição. \\
\hline & 3 & Disponibiliza os códigos e regulamentos do município. \\
\hline & 4 & $\begin{array}{l}\text { Disponibiliza as informaç̃̃es do orçamento, relatórios contábeis, anexos da LRF, informações das licitações em } \\
\text { andamento, editais etc. }\end{array}$ \\
\hline & 5 & Disponibiliza as informações sobre os cargos, competências e salários dos servidores. \\
\hline & 6 & Disponibiliza as informações sobre concurso público, editais, gabaritos de provas. \\
\hline & 7 & Permite a cópia de documentos públicos, por meio de impressão, download. \\
\hline & 8 & $\begin{array}{l}\text { Os documentos públicos devem ter referências corretas, ausência de erros de digitação, grafia ou gramática; } \\
\text { identificação das fontes ou dos responsáveis, meios de estabelecer contato; conteúdo em linguagem clara, tom } \\
\text { profissional, ausência de preconceitos no discurso e informação livre de publicidade. }\end{array}$ \\
\hline & 9 & $\begin{array}{l}\text { Disponibiliza informações sobre a gestão de emergências, utilizando o site como mecanismo de alerta para } \\
\text { problemas naturais ou provocados pelo homem. }\end{array}$ \\
\hline & 10 & Publica as ofertas de empregos, de treinamento e recursos de encaminhamento de currículo pelo interessado. \\
\hline & 11 & Disponibiliza calendário de eventos da comunidade, um quadro de anúncios/informações. \\
\hline & 12 & $\begin{array}{l}\text { Disponibiliza informações com atribuição de responsabilidade formal pelo conteúdo e pela atualização das } \\
\text { páginas. }\end{array}$ \\
\hline & 13 & Disponibiliza em seu site os arquivos de áudio e vídeo de eventos públicos, palestras, encontros. \\
\hline \multirow{12}{*}{ 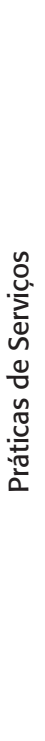 } & 14 & Disponibiliza e-mails, telefones e endereços para solicitar informações. \\
\hline & 15 & A página principal é personalizada para facilitar o acesso do cidadão aos serviços. \\
\hline & 16 & $\begin{array}{l}\text { Permite acesso a informações privadas utilizando senhas, como em registros criminais, educacionais, médicos, } \\
\text { cadastro civil. }\end{array}$ \\
\hline & 17 & $\begin{array}{l}\text { Permite o acesso a informações relacionadas à educação, indicadores econômicos, instituições educacionais, } \\
\text { meio ambiente, saúde, transporte. }\end{array}$ \\
\hline & 18 & Identifica o responsável ou gerenciador do site para possível contato ou responsabilização. \\
\hline & 19 & Disponibiliza um relatório das violações de leis e regulamentos administrativos. \\
\hline & 20 & Disponibiliza um mecanismo para submissão, monitoramento e eliminação de queixas/denúncias públicas. \\
\hline & 21 & Disponibiliza as notícias e informações sobre políticas públicas. \\
\hline & 22 & $\begin{array}{l}\text { Permite o pagamento de impostos, taxas, contribuições de melhorias, multas. Essa prática deve permitir o acesso a in- } \\
\text { formações, preenchimento de guias, cálculo do tributo e possível multa de juros, inclusive o pagamento on-line. }\end{array}$ \\
\hline & 23 & Permite a consulta a dados cadastrais, débitos de IPTU e ISS, emissão de guias para pagamento de multa. \\
\hline & 24 & $\begin{array}{l}\text { Permite a obtenção eletrônica de documentos tributários, como: consultas e certidões tributárias, nota fiscal } \\
\text { eletrônica etc. }\end{array}$ \\
\hline & 25 & Permite o registro do cidadão e/ou empresa para serviços on-line. \\
\hline
\end{tabular}




\begin{tabular}{|c|c|c|}
\hline \multirow{4}{*}{ 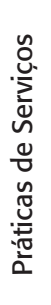 } & 26 & $\begin{array}{l}\text { Concede licenças, registros ou permissões, como: licença sanitária, licença/registro de cães e outros animais, } \\
\text { licença para abrir e fechar estabelecimentos, permissões para construção. }\end{array}$ \\
\hline & 27 & Permite a compra de bilhetes para eventos. \\
\hline & 28 & $\begin{array}{l}\text { Possui um mecanismo de compras eletrônicas mediante a realização de leilões on-line - pregão eletrônico } \\
\text { - que consiste em um pregão via internet para negociações, automáticas e abertas, entre os órgãos do Estado, } \\
\text { os compradores e os fornecedores do setor privado. }\end{array}$ \\
\hline & 29 & Publica os editais de abertura de licitações e seus respectivos resultados. \\
\hline \multirow{10}{*}{ 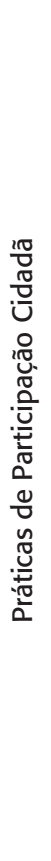 } & 30 & Possui boletim informativo on-line. \\
\hline & 31 & Disponibiliza informações de governança. \\
\hline & 32 & $\begin{array}{l}\text { Disponibiliza um e-mail para contato, com a descrição da política adotada de resposta, começando com o tempo } \\
\text { e a data de recepção, o prazo estimado para resposta, o que fazer se a resposta não foi recebida e uma cópia } \\
\text { da sua mensagem original. }\end{array}$ \\
\hline & 33 & $\begin{array}{l}\text { Disponibiliza um quadro de anúncios, bate-papo, fórum de discussão, chats, para discutir questões políticas, eco- } \\
\text { nômicas e sociais, com os gestores eleitos, órgãos específicos, especialistas, facilitando o diálogo entre prefeito e } \\
\text { cidadãos, com verdadeira possibilidade de participação. }\end{array}$ \\
\hline & 34 & $\begin{array}{l}\text { Disponibiliza a agenda de reuniões ou calendário das discussões públicas, incluindo o tempo, lugar, agenda e } \\
\text { informações sobre os depoimentos dos cidadãos, participação, observação ou opções. }\end{array}$ \\
\hline & 35 & $\begin{array}{l}\text { Fazer pesquisas ou sondagens, breves ou mais detalhadas, de satisfação, opinião, manifestação de preferências } \\
\text { e sugestões, para verificar a percepção do cidadão quanto aos serviços prestados e à própria estrutura de gover- } \\
\text { nança eletrônica. }\end{array}$ \\
\hline & 36 & Disponibiliza um canal específico para encaminhamento de denúncias. \\
\hline & 37 & $\begin{array}{l}\text { Disponibiliza informações biográficas, e-mail, telefone, fotografia, endereço para contato com os gestores eleitos } \\
\text { e membros da gestão municipal. }\end{array}$ \\
\hline & 38 & Disponibiliza a estrutura e as funções da prefeitura. \\
\hline & 39 & $\begin{array}{l}\text { Disponibiliza um link específico para "democracia" ou "participação cidadã" na página principal do seu site, que } \\
\text { o leva a uma seção especial, detalhando a finalidade e missão das unidades públicas, os decisores de alto nível, } \\
\text { permitindo ligações com a legislação, orçamento e outros detalhes de informações de accountability. }\end{array}$ \\
\hline \multirow{8}{*}{ 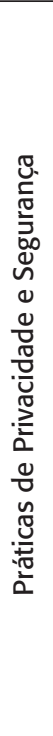 } & 40 & $\begin{array}{l}\text { Declara a política de privacidade no site, descrevendo os tipos de informações recolhidas e as políticas de utilização } \\
\text { e partilha das informações pessoais, identificando os coletores das informações, disponível em todas as páginas } \\
\text { que aceitam os dados, e com a data em que a política de privacidade foi revisada. }\end{array}$ \\
\hline & 41 & $\begin{array}{l}\text { Permite diminuir a divulgação de informações pessoais, dispondo da possibilidade de entrar e sair do fornecimento } \\
\text { das informações. }\end{array}$ \\
\hline & 42 & Permite que o usuário revise os dados pessoais e conteste os registros de informações incompletas ou erradas. \\
\hline & 43 & $\begin{array}{l}\text { Informa as práticas antes de qualquer informação pessoal ser coletada, evidenciando a entidade que está obtendo } \\
\text { a informação, o propósito do recolhimento, potenciais recebedores, natureza da informação, meios de coleta, se } \\
\text { as informações são voluntárias ou obrigatórias e a consequência do não fornecimento. }\end{array}$ \\
\hline & 44 & $\begin{array}{l}\text { Limita o acesso de dados e garante que não será utilizado para fins não autorizados, utilizando senhas e criptografia } \\
\text { de dados sensíveis e procedimentos de auditoria. }\end{array}$ \\
\hline & 45 & $\begin{array}{l}\text { Disponibiliza endereço de contato, telefone e/ou e-mail, específicos para denúncias, críticas, sobre a política de } \\
\text { privacidade e segurança. }\end{array}$ \\
\hline & 46 & $\begin{array}{l}\text { Permite o acesso a informações públicas por meio de uma área restrita que exija senha e/ou registro, como o } \\
\text { uso de assinatura digital para identificar os usuários. }\end{array}$ \\
\hline & 47 & $\begin{array}{l}\text { Permite acesso a informações não públicas para os servidores, mediante uma área restrita que exija senha e/ou } \\
\text { registro. }\end{array}$ \\
\hline
\end{tabular}




\begin{tabular}{|c|c|c|}
\hline & 48 & O tamanho da home page (página inicial do site) deve ter no máximo dois comprimentos da tela. \\
\hline & 49 & $\begin{array}{l}\text { Determina o público-alvo do site, com canais personalizados para grupos específicos, como cidadãos, empresas } \\
\text { ou outros órgãos públicos. }\end{array}$ \\
\hline & 50 & $\begin{array}{l}\text { A barra de navegação deve conter os itens agrupados na área de navegação, utilizando termos claros para definir } \\
\text { as opções de navegação de categorias, ícones de navegação de reconhecimento imediato da classe de itens, } \\
\text { links identificados. }\end{array}$ \\
\hline & 51 & $\begin{array}{l}\text { Fornece links clicáveis para a página inicial em todas as páginas, para os departamentos governamentais e para } \\
\text { sites relacionados fora do governo. }\end{array}$ \\
\hline & 52 & Disponibiliza na página principal um mapa do site ou esboço de todos os sites. \\
\hline$\frac{\pi}{\pi}$ & 53 & $\begin{array}{l}\text { As páginas devem ser constituídas com cores padrão e consistentes, com adequação de estilos de fonte, forma- } \\
\text { tação de texto, visibilidade dos elementos, critério para uso de logotipos. }\end{array}$ \\
\hline$\overline{\tilde{n}}$ & 54 & Os textos devem ser sublinhados indicando os links. \\
\hline$\stackrel{0}{\alpha}$ & 55 & Disponibiliza a data da última atualização das páginas. \\
\hline $\begin{array}{l}\frac{\pi}{\pi} \\
\stackrel{\underline{\pi}}{\underline{\underline{0}}}\end{array}$ & 56 & $\begin{array}{l}\text { Fornece um link para informações sobre o governo, com a possibilidade de contato, com endereço, telefone, } \\
\text { fax ou e-mail. }\end{array}$ \\
\hline$\frac{3}{3}$ & 57 & Disponibiliza versões alternativas de documentos longos, como arquivos em PDF ou DOC. \\
\hline 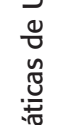 & 58 & $\begin{array}{l}\text { Permite que os campos dos formulários sejam acessíveis por meio das teclas ou do cursor, identificando clara- } \\
\text { mente aqueles com preenchimentos obrigatórios, fazendo com que a ordem das guias dos campos seja lógica, } \\
\text { ou seja, com o toque na tecla "tab" passe para o próximo campo. }\end{array}$ \\
\hline ڤ & 59 & Disponibiliza informações de como identificar e corrigir erros submetidos. \\
\hline & 60 & Dispõe de um site de busca ou um link no próprio site do governo. \\
\hline & 61 & $\begin{array}{l}\text { Dispõe de seu próprio mecanismo de pesquisa, permitindo que as pesquisas sejam feitas de forma específica, } \\
\text { por secretaria, em todo o site; com recursos de pesquisas avançadas, como a utilização de palavras, frases exatas, } \\
\text { combinação; com capacidade para classificar os resultados da pesquisa por relevância ou outros critérios. }\end{array}$ \\
\hline & 62 & Disponibiliza um mecanismo de acesso aos portadores de necessidades especiais. \\
\hline & 63 & Disponibiliza os conteúdos do site em mais de um idioma. \\
\hline & 64 & Disponibiliza os conteúdos de áudio com transcrições escritas e/ou legendas. \\
\hline & 65 & Permite o acesso ao site e seus conteúdos por meio do teclado do computador. \\
\hline
\end{tabular}

Fonte: adaptado de Mello (2009).

Os dados relativos às práticas de governança eletrônica foram obtidos nos websites oficiais dos estados brasileiros. Na formação do índice, para cada prática, foi atribuída nota 0 (zero) ou 1 (um), sendo 1 para as informações que representaram boas práticas de governança e 0 para aquelas que não possuíam. Todas as questões receberam o mesmo peso e ao final cada empresa obteve uma pontuação que variou de 0 (representando $0 \%$ de adesão) a 65 (representando 100\% de adesão às práticas de governança eletrônica). Esta forma de coletar os dados difere da que foi realizada por Mello (2009), que adotou uma escala de 0 a 3 para a coleta de dados, diferenciando o grau de adesão a uma prática específica, no entanto é condizente com a pesquisa de Moura e colaboradores (2011).

Na sequência, foi calculada a eficiência no uso das receitas pelos estados, para identificar as regiões brasileiras que apresentam melhor combinação da receita total (receita corren- 
te, receita de capital) relacionada com seu Índice de Desenvolvimento Humano (IDH), Produto Interno Bruto (PIB) e tamanho. O IDH foi medido pelo indicador total do IDH estadual, obtido no site do Programa das Nações Unidas para o Desenvolvimento (Pnud) e refere-se ao ano de 2006. O PIB foi mensurado pelo valor do produto interno bruto per capita de cada estado, obtido no site do Instituto Brasileiro de Geografia e Estatística (IBGE) e refere-se ao ano de 2009. O tamanho foi medido pela população de cada município, com dados obtidos no site do IBGE e refere-se ao ano de 2010. A utilização dos índices, nesses respectivos anos, deu-se por serem os resultados mais recentes divulgados para a amostra no momento da realização da pesquisa.

Para o cálculo da eficiência foi utilizado o software estatístico DEA-Solver, cujo modelo matemático do DEA (Análise Envoltória de Dados), de acordo com Kassai (2002), foi proposto, inicialmente, por Charnes, Cooper e Rhodes, em 1978 e que, segundo Charnes e colaboradores (1994), possui dois modelos básicos geralmente usados nas aplicações. O primeiro é o CCR (Charnes, Cooper e Rhodes, 1978), também conhecido como Constant ReturnstoScale (CRS), avalia a eficiência total, identifica as Unidades de Análises - DMUs eficientes e ineficientes, e determina a que distância da fronteira de eficiência estão as unidades ineficientes. O segundo, adotado nesta pesquisa, é o modelo BCC (Banker, Charnes e Cooper, 1984), também conhecido como VariableReturnstoScale (VRS), utiliza uma formulação que permite a projeção de cada DMU ineficiente sobre a superfície de fronteira (envoltória) determinada pelas DMUs eficientes de tamanho compatível.

DEA, conforme descreve Zhu (2000), é uma técnica baseada em programação linear, projetada para estabelecer uma medida de eficiência relativa entre diferentes entidades de um gênero comum. O autor destaca ainda que o modelo DEA representa uma das mais adequadas ferramentas para avaliar a eficiência, em comparação com ferramentas convencionais. O cálculo, segundo Zhu (2000), mostra o quanto uma instituição é eficiente, no tratamento de seus inputs e outputs, em relação às outras, numa análise que fornece um indicador que varia de 0 a 1 . Somente as instituições que obtêm índice de eficiência igual a 1 é que fazem parte da fronteira eficiente.

Nesta pesquisa, avaliaram-se as melhores combinações de receitas relacionadas com IDH, PIB e tamanho. No quadro 2 apresenta-se a formação das Unidades de Análise — DMU.

Quadro 2

Definição das unidades de análise ou conceito de eficiência

\begin{tabular}{|c|c|c|c|c|c|}
\hline DMU & Input 1 & Input 2 & Output 1 & Output 2 & Output 3 \\
\hline Estados & Rec. Correntes & Rec. de Capital & PIB & IDH & Tamanho \\
\hline
\end{tabular}

Fonte: dados da pesquisa.

Neste estudo, diferente dos estudos de Huther e Shah (1999), Mello (2009) e Moura e colaboradores (2011), foram avaliadas as combinações entre as receitas públicas utilizadas e 
os indicadores socioeconômicos e tamanho, para então relacioná-los com as práticas de governança eletrônica. Acredita-se que essa alternativa é mais adequada, já que possibilita verificar quais estados são mais eficientes ao considerar todas as variáveis. Avaliar os indicadores de maneira isolada, não considerando qual estado é mais eficiente no conjunto, pode prejudicar a análise.

Desse modo, inicialmente calculou-se o índice de governança eletrônica de cada estado brasileiro. Em seguida, foram coletados os valores correspondentes às receitas, PIB, IDH, tamanho, para calcular a eficiência na utilização dos recursos públicos pelos estados, por meio do DEA. Utilizou-se ainda na análise estatística o teste de Kolmogorov-Smirnov, a fim de testar se a distribuição amostral possuía normalidade dos dados. O resultado do teste foi positivo, portanto, optou-se por utilizar o coeficiente de correlação de Pearson para verificar a correlação existente entre os índices da pesquisa.

\section{Descrição e análise dos dados}

Esta seção contém a descrição e análise dos dados coletados. Primeiramente, apresentam-se as estatísticas descritivas do índice de governança eletrônica dos estados brasileiros, por regiões. Em seguida, expõem-se as estatísticas descritivas do cálculo da eficiência da combinação de receitas correntes e receitas de capital relacionadas com IDH, PIB e tamanho. E, por último, demonstram-se os resultados da correlação de Pearson, que possibilitou alcançar o objetivo da pesquisa.

\section{Tabela 1}

Estatística descritiva do índice de governança eletrônica

\begin{tabular}{|c|c|c|c|c|c|}
\hline Regiões & $\begin{array}{c}\text { № } \\
\text { Estados }\end{array}$ & $\begin{array}{c}\text { Mínimo } \\
\%\end{array}$ & $\begin{array}{c}\text { Máximo } \\
\%\end{array}$ & $\begin{array}{l}\text { Média } \\
\%\end{array}$ & $\begin{array}{c}\text { Desvio Pad. } \\
\%\end{array}$ \\
\hline Centro-Oeste & 3 & 43 & 57 & 51 & 7 \\
\hline Nordeste & 9 & 48 & 74 & 58 & 10 \\
\hline Norte & 7 & 42 & 72 & 56 & 11 \\
\hline Sudeste & 4 & 58 & 72 & 64 & 6 \\
\hline Sul & 3 & 54 & 66 & 61 & 6 \\
\hline Totais & 26 & 42 & 74 & 58 & 9 \\
\hline
\end{tabular}

Fonte: dados da pesquisa.

Nota-se na tabela 1 que a melhor média (64\%) de adoção das práticas de governança eletrônica refere-se à região Sudeste. O índice mínimo dessa região foi de $58 \%$, obtido pelo estado de Minas Gerais, e o máximo foi de 72\%, conquistado pelo estado de São Paulo. O desvio padrão dessa região foi de apenas $6 \%$, demonstrando baixa variabilidade nos índices. 
Os estados da região Sul também se destacaram, pois, em média, possuem $61 \%$ das práticas de governança eletrônica analisadas, o índice mínimo foi de 54\% do estado de Santa Catarina e o máximo foi de $66 \%$, obtido pelo estado do Rio Grande do Sul. O desvio padrão dessa região também foi baixo, demonstrando certa homogeneidade.

A região Norte possui o estado com menor índice de governança eletrônica da amostra, com apenas $42 \%$ das práticas consultadas. Esse índice foi obtido pelo estado de Rondônia, e o índice máximo dessa região foi de $72 \%$, proveniente do estado do Amazonas.

De forma geral, tem-se um índice médio de governança de 58\%, muito distante de 100\%. O estado com menor índice alcançou somente $42 \%$ de um total de 65 itens analisados, enquanto o máximo atingindo foi de 74\%. Ressalta-se, no entanto, que nenhum estado atingiu 100\% de adesão às práticas de governança eletrônica analisadas e que as regiões CentroOeste e Norte apresentaram os índices médios mais baixos.

No entanto, ao comparar os resultados desta pesquisa com os de Mello (2009), que investigou a qualidade das práticas de governança eletrônica dos estados brasileiros no ano de 2009 e encontrou um índice médio no período de 50\%, percebe-se que houve uma melhora nas práticas de governança eletrônica. Esse resultado confirma os relatos de Bhuiyan (2011), de que a governança eletrônica é um fenômeno que vem se desenvolvendo de maneira crescente nas organizações públicas de diversos países por todo o mundo.

Cabe destacar que esse desenvolvimento pode ser reflexo de mudanças sociais, econômicas e políticas em âmbito mundial, que impactam em reformas na administração pública e que tornam os cidadãos mais exigentes e interessados nos atos públicos, conforme descrevem Mello (2009), Potnis (2010) e Janowski, Pardo e Davies (2012). Ou ainda, devido ao aumento de imposições legais, tais como a Lei Complementar no 131 , aprovada em maio de 2009, a qual determina que o gestor público disponibilize, em tempo real, informações detalhadas sobre a execução orçamentária e financeira da União, dos estados, do Distrito Federal e dos municípios.

Na tabela 2 apresentam-se as estatísticas descritivas do cálculo da eficiência na utilização dos recursos públicos, ou seja, eficiência na combinação de receitas correntes e receitas de capital com IDH, PIB e tamanho.

Tabela 2

Estatísticas descritivas do cálculo da eficiência na utilização dos recursos públicos pelos estados

\begin{tabular}{|c|c|c|c|c|c|}
\hline Regiões & $\begin{array}{c}\text { № } \\
\text { Estados }\end{array}$ & $\begin{array}{c}\text { Mínimo } \\
\%\end{array}$ & $\begin{array}{c}\text { Máximo } \\
\%\end{array}$ & $\begin{array}{l}\text { Média } \\
\%\end{array}$ & $\begin{array}{c}\text { Desvio Pad. } \\
\%\end{array}$ \\
\hline Centro-Oeste & 3 & 0,95 & 1 & 0,98 & 0,0308 \\
\hline Nordeste & 9 & 0,86 & 1 & 0,96 & 0,0539 \\
\hline Norte & 7 & 0,76 & 1 & 0,94 & 0,0921 \\
\hline Sudeste & 4 & 1 & 1 & 1 & 0 \\
\hline Sul & 3 & 1 & 1 & 1 & 0 \\
\hline Totais & 26 & 0,76 & 1 & 0,97 & 0,060 \\
\hline
\end{tabular}

Fonte: dados da pesquisa. 
Observa-se na tabela 2 que todos os estados das regiões Sudeste e Sul apresentaram score 1, significando que, na amostra analisada, esses estados podem ser considerados mais eficientes, ou seja, possuem melhor combinação de receitas correntes e receitas de capital com IDH, PIB e tamanho.

A região Norte apresentou a menor média $(0,94)$, mas quatro estados atingiram score 1 e também podem ser considerados eficientes. Os estados eficientes dessa região foram: Amapá, Amazonas, Pará e Roraima. Os estados que não atingiram score 1 foram: Acre, Rondônia e Tocantins, com scores 0,92, 0,89 e 0,76, respectivamente.

Os estados da região Nordeste atingiram score médio de 0,96 e, entre os nove estados, quatro obtiveram score 1, podendo ser considerados eficientes. São eles: Bahia, Maranhão, Pernambuco e Sergipe. Os estados de Alagoas, Paraíba, Piauí, Ceará e Rio Grande do Norte, com scores 085, 0,88, 0,93, 0,95 e 0,96, respectivamente, possuem menor eficiência na utilização dos recursos públicos.

A região Centro-Oeste apresentou média de 0,98 e, entre os estados desta região, Mato Grosso e Goiás obtiveram score 1 e demonstraram-se mais eficientes que o estado do Mato Grosso do Sul, que obteve score 0,95.

De forma geral, os cálculos obtidos por meio do DEA demonstraram que, dos 26 estados, 17 deles atingiram score 1, ou seja, a maioria dos estados brasileiros é eficiente na utilização dos recursos públicos. Analisar eficiência, segundo Silva et al. (2012), é importante e necessário, no sentido de desenvolver políticas que ampliem e melhorem a atuação dos gestores públicos.

Na tabela 3 evidenciam-se os coeficientes de correlação de Pearson a fim de verificar se há correlação entre práticas de governança eletrônica e eficiência na utilização dos recursos públicos.

Tabela 3

Correlação das variáveis

\begin{tabular}{|lcc|}
\hline Índices & Governança eletrônica & $\begin{array}{c}\text { Eficiência na utilização } \\
\text { das receitas }\end{array}$ \\
\hline Governança eletrônica & 1 & \\
Eficiência na utilização das receitas & $0,55^{* *}$ & 1 \\
\hline
\end{tabular}

Fonte: dados da pesquisa.

** Correlação estatisticamente significativa ao nível de significância de 0,01.

Verifica-se na tabela 3 que a variável índice de governança eletrônica tem correlação positiva e moderada de 55\% com a variável eficiência na utilização das receitas públicas, e estatisticamente significativa a um nível de significância de 0,01. Portanto, os resultados sinalizam que entre os estados brasileiros aqueles com melhores práticas de governança eletrônica foram os que apresentaram maior eficiência na utilização dos recursos públicos, ou seja, melhor combinação de receitas correntes e receitas de capital com IDH, PIB e tamanho. 
Os resultados desta pesquisa corroboram os encontrados por Mello (2009), que verificou que os estados mais desenvolvidos com maior PIB, maior IDH e menor Gini eram aqueles mais bem classificados com maior número de práticas de governança eletrônica implantadas. Também coadunam com os de Moura e colaboradores (2011), que constataram que municípios maiores e com melhores condições socioeconômicas representadas pelo IDH e PIB aderiram a um maior número de práticas de governança eletrônica.

Depreende-se que a combinação entre receitas públicas utilizadas e os indicadores socioeconômicos e tamanho são variáveis que também contribuem para explicar a utilização de práticas de governança eletrônica nos estados brasileiros. Assim, os resultados sinalizam que, no conjunto, uma melhoria nas condições socioeconômicas, tamanho e utilização de receitas pode proporcionar aumento na adoção das práticas de governança eletrônica.

\section{Considerações finais}

A pesquisa objetivou analisar as práticas de governança eletrônica dos estados brasileiros e sua correlação com a eficiência na utilização das receitas. Para tal, realizou-se pesquisa descritiva, conduzida por meio de análise documental, com abordagem quantitativa. A amostra intencional e não probabilística compreendeu os 26 estados brasileiros.

No cálculo do índice de governança eletrônica, pautado nos itens do constructo da pesquisa de Mello (2009), para avaliar as práticas de governança dos estados brasileiros, observou-se que os estados com melhores práticas de governança eletrônica localizam-se na região Sudeste. Os estados da região Sul também se destacaram, pois, em média, possuem 61\% das práticas de governança eletrônica analisadas.

De forma geral, o índice médio de governança foi de 58\%, muito distante de $100 \%$. O estado com menor índice alcançou somente $42 \%$ de um total de 65 itens analisados, enquanto o máximo atingindo foi de 74\%. Ressalta-se o fato de que nenhum estado atingiu 100\% de adesão às práticas de governança eletrônica analisadas, e que as regiões Centro-Oeste e Norte apresentaram os índices médios mais baixos.

Em relação à eficiência na utilização das receitas, os cálculos pelo modelo DEA demonstraram que todos os estados das regiões Sudeste e Sul apresentaram score 1. Portanto, foram os mais eficientes da amostra, ou seja, apresentaram uma melhor combinação de receitas correntes e receitas de capital com IDH, PIB e tamanho. A região Norte apresentou a menor média $(0,94)$ de eficiência, mas quatro estados dessa região também atingiram score 1 .

Por fim, os coeficientes de correlação de Pearson evidenciaram que a variável índice de governança eletrônica possui correlação positiva com a variável eficiência na utilização das receitas. Assim, os resultados foram condizentes com pesquisas anteriores que constataram que tamanho, PIB e IDH, de maneira isolada, relacionam-se com maior adoção de práticas de governança eletrônica.

Portanto, os resultados sinalizam que a combinação entre receitas públicas utilizadas e os indicadores socioeconômicos e tamanho também são variáveis que contribuem para expli- 
car a utilização de práticas de governança eletrônica nos estados brasileiros. Portanto, conclui-se que a melhoria nas condições socioeconômicas, tamanho e utilização de receitas pode se refletir em aumento na utilização das práticas de governança eletrônica.

Os resultados despertam interesses para novas pesquisas sobre governança eletrônica. Recomenda-se inicialmente acompanhar os índices de governança eletrônica e de eficiência na utilização das receitas nos estados brasileiros. Também seria interessante realizar esta análise nos municípios brasileiros e verificar se existe relação entre o nível de eficiência constatado nos estados e o dos municípios.

\section{Referências}

AKUTSU, Luiz. Sociedade da informação, accountability e democracia delegativa: investigação em portais de governo no Brasil. Dissertação (mestrado) - Escola de Administração, Universidade Federal da Bahia, Salvador, 2002.

AKUTSU, Luiz; PINHO, José A. G. Sociedade da informação, accountability e democracia delegativa: investigação em portais de governo no Brasil. Revista de Administração Pública, Rio de Janeiro, v. 36, n. 5, set./out. 2002.

ARAÚJO, Wagner F. G.; LAIA, Marconi M. Governança eletrônica e gestão da informação em portais de governo: uma análise da reestruturação do Portal Minas. In: ENCONTRO ANUAL DA ASSOCIAÇÃO NACIONAL DOS PROGRAMAS DE PÓS-GRADUAÇÃO EM ADMINISTRAÇÃO, 28., 2004, Curitiba. Anais... Rio de Janeiro: Anpad, 2004. p. 1-16.

BANKER, Rajiv D.; CHARNES, Abraham; COOPER, William W. Models for estimating technical and scale inefficiencies in data envelopment analysis. Management Science, v. 30, n. 9, p. 1078-1092, 1984.

BHUIYAN, Shahjahan H. Modernizing Bangladesh public administration through e-governance: benefits and challenges. Government Information Quarterly, v. 28, p. 54-65, 2011.

BRASIL. Lei Complementar no 101, de 04/05/2000. Lei de Responsabilidade Fiscal. Estabelece normas de finanças públicas voltadas para a responsabilidade na gestão fiscal e dá outras providências.

BRASIL. Lei Complementar no 131, de 27/05/2005. Acrescenta dispositivos à Lei Complementar no 101 , de 4 de maio de 2000, que estabelece normas de finanças públicas voltadas para a responsabilidade na gestão fiscal e dá outras providências, a fim de determinar a disponibilização, em tempo real, de informações pormenorizadas sobre a execução orçamentária e financeira da União, dos Estados, do Distrito Federal e dos Municípios.

BRASIL. Lei no 4.320, de 17 de março de 1964. Estatui normas gerais de direito financeiro para elaboração e controle dos orçamentos e balanços da União, dos Estados, dos Municípios e do Distrito Federal. Disponível em: <www.planalto.gov.br/ccivil_03/Leis/L4320.htm>. Acesso em: 3 dez. 2011. 
BRASIL. Ministério do Planejamento, Orçamento e Gestão. Secretaria de Orçamento Federal. Manual técnico de orçamento MTO. Versão 2013. Brasília, 2012.

BRÜCKNER, Markus. An instrumental variables approach to estimating tax revenue elasticities: Evidence from Sub-Saharan Africa. Journal of Development Economics, v. 98, p. 220-227, 2012.

BUCOVETSKY, Sam; SMART, Michael. The efficiency consequences of local revenue equalization: tax competition and tax distortions. Journal of Public Economic Theory, v. 8, p. 119-144, 01, 2006.

CARVALHO, Deusvaldo. Orçamento e contabilidade pública: teoria, prática e mais de 800 exercícios. 4. ed. Rio de Janeiro: Elsevier, 2008.

CHARNES, Abraham et al. Data envelopment analysis. 2 ed. Boston: Kap, 1994.

CHARNES, Abraham; COOPER, William W.; RHODES, Edwardo. Measuring the efficiency of decision making units. European Journal of Operational Research, v. 2, p. 429-444, 1978.

EVANS, Donna; YEN, David C. E-government: evolving relationship of citizens and government, domestic, and international development. Government Information Quarterly, v. 23, n. 2, p. 207235, 2006.

FERREIRA, Maria P.; PITTA, Marcelo T. Avaliação da eficiência técnica na utilização dos recursos do Sistema Único de Saúde na produção ambulatorial. São Paulo em Perspectiva, v. 22, n. 2, p. 5571, 2008.

GEORGESCU, Mircea. The government in the digital age: myths, realities and promises. Social Science Research Network - SSRN. 2008. Disponível em: <http://ssrn.com/abstract=906587>. Acesso em: 26 out. 2012.

HOLZER, Marc; KIM, Seang-Tae. Digital governance in municipalities worldwide: a longitudinal assessment of municipal websites throughout the world. Division for Public Administration and Development Management Department of Economic and Social Affairs, United Nations. 2005. Disponível em: <http://unpan1.un.org/intradoc/groups/public/documents/aspa/unpan031374. pdf $>$. Acesso em: 5 dez. 2011.

HUTHER, Jeff; SHAH, Anwar. Applying a simple measure of good governance to the debate on fiscal decentralization. Social Science Research Network - SSRN. Nov. 1999. Disponível em:<wwwwds.worldbank.org/external/default/WDSContentServer/IW3P/IB/2000/02/24/00 0178830_98111703530240/Rendered/PDF/multi_page.pdf>. Acesso em: 5 dez. 2011.

JANOWSKI, Tomasz; PARDO, Theresa A.; DAVIES, Jim. Government information networks: mapping electronic governance cases through public administration concepts. Government Information Quarterly, v. 29, p. S1-S10, 2012.

JUND, Sergio. Administração, orçamento e contabilidade pública: teoria e 830 questões. 2. ed. Rio de Janeiro: Elsevier, 2006.

KASSAI, Silvia. Utilização da Análise por Envoltória de Dados (DEA) na análise de demonstrações contábeis. Tese (doutorado em economia) — Universidade de São Paulo, São Paulo, 2002. 
LEAL, Ricardo P. C.; CARVALHAL-DA-SILVA, André L. Corporate governance and value in Brazil (and in Chile). In: CHONG, A.; LOPES-DE-SILANES, F. (Org.). Investor protection and corporate governance: firm level evidence across Latin America. Palo Alto, CA: Stanford University Press, 2007. p. 213-287.

LOPES, Alexsandro B.; WALKER, Martin. Firm-level incentives and the informativeness of accounting reports: an experiment in Brazil (February 1, 2008). Disponível em: <http://ssrn.com/abstract $=1095781>$ e < http://dx.doi.org/10.2139/ssrn.1095781>. Acesso em: 5 dez. 2011.

MELLO, Gilmar R. Estudo das práticas de governança eletrônica: instrumento de controladoria para a tomada de decisões na gestão dos estados brasileiros. Tese (doutorado) — Universidade de São Paulo, São Paulo, 2009.

MORAES, Patricia B. Cidade, comunicação e tecnologia da informação: uma análise de portais governamentais brasileiros. Dissertação (mestrado) — Faculdade de Comunicação, Universidade Federal da Bahia, Salvador, 2004.

MOURA, Geovanne D. et al. Análise das práticas de governança eletrônica de municípios do Estado de Santa Catarina. In: ENCONTRO DE ADMINISTRAÇÃO DA INFORMAÇÃO, 3., Porto Alegre, 2011. Anais... Rio de Janeiro: Anpad, 2011. p. 1-16.

NARAYAN, Paresh K. The government revenue and government expenditure nexus: empirical evidence from nine Asian countries. Journal of Asian Economics, v. 15, p. 1203-1216, 2005.

OKOT-UMA, Rogers W'O. Electronic governance: re-inventing good governance. 2000. Disponível em: < http://webworld.unesco.org/publications/it/egov/wordbank/20okotuma.pdf>. Acesso em: 5 dez. 2011.

PINHO, José A. G. Investigando portais de governo eletrônico de estados no Brasil: muita tecnologia, pouca democracia. RAP — Revista de Administração Pública, v. 3, n. 42, p. 471-93, maio/jun. 2008.

POTNIS, Devendra D. Measuring e-Governance as an innovation in the public sector. Government Information Quarterly, v. 27, n. 1, p. 41-48, 2010.

PRADO, Otavio. Governo eletrônico e transparência: a publicização das contas públicas das capitais brasileiras. Dissertação (mestrado) — Escola de Administração de Empresas de São Paulo, Fundação Getulio Vargas, São Paulo, 2004.

QUINTANA, Alexandre C. et al. Contabilidade pública: de acordo com as novas normas brasileiras de contabilidade aplicadas ao setor público e a Lei de Responsabilidade Fiscal. São Paulo: Atlas, 2011.

REZENDE, Denis A.; ABREU, Aline F. Tecnologia da informação aplicada a sistemas de informação empresariais: o papel estratégico da informação e dos sistemas de informação nas empresas. 3. ed. São Paulo: Atlas, 2003.

REZENDE, Denis A.; FREY, Klaus F. Administração estratégica e governança eletrônica na gestão urbana. Revista Eletrônica de Gestão de Negócios, v. 1, n. 1, p. 51-59, 2005. 
RIBEIRO, Manuella M. Como o governo eletrônico pode aumentar a transparência das compras governamentais? In: CONGRESSO CONSAD DE GESTÃO PÚBLICA, 1., 2008, Brasília. Anais... Brasília, 2008. p. 1-15.

RIECKEN, Rinalda. Governo eletrônico em administrações locais brasileiras: avaliação de progresso, fatores intervenientes e critérios de priorização de iniciativas. Tese (doutorado em ciência da informação) - Programa de Pós-Graduação em Ciência da Informação da Universidade de Brasília, Brasília, 2008.

SILVA, Ambrosina A. P. et al. Eficiência na alocação de recursos públicos destinados à educação, saúde e habitação em municípios mineiros. Contabilidade, Gestão e Governança, v. 15, n. 1, p. 96114, 2012.

SILVA, Juliano M.; CORREA, Patricia S. A. Governança eletrônica e o empreendedorismo: uma análise dos sites das prefeituras do estado do Paraná. In: ENCONTRO ANUAL DA ASSOCIAÇÃO NACIONAL DOS PROGRAMAS DE PÓS-GRADUAÇÃO EM ADMINISTRAÇÃO, 30., 2006, Salvador. Anais... Rio de Janeiro: Anpad, 2006. p. 1-16.

SILVEIRA, Alexandre D. M. et al. Endogeneity of Brazilian corporate governance quality determinants. Journal of Corporate Governance, v. 10, n. 2, p. 191-202, 2010.

SOARES JUNIOR, Jair S.; SANTOS, Ernani M. Governança eletrônica: uma perspectiva sociotécnica das organizações públicas a partir da padronização e interoperabilidade. In: ENCONTRO ANUAL DA ASSOCIAÇÃO NACIONAL DOS PROGRAMAS DE PÓS-GRADUAÇÃO EM ADMINISTRAÇÃO, 31., 2007, Rio de Janeiro. Anais... Rio de Janeiro: Anpad, 2007. p. 1-16.

ZHU, Joe. Multi-factor performance measure model with application to fortune 500 companies. European Journal of Operational Research, v. 123, n. 1, p. 105-124, 2000.

Ilse Maria Beuren é professora do Programa de Pós-Graduação em Ciências Contábeis da Universidade Federal do Paraná (UFPR). E-mail: ilse.beuren@gmail.com.

Geovanne Dias de Moura é doutorando do Programa de Pós-Graduação em Ciências Contábeis da Universidade Regional de Blumenau (Furb). E-mail: geomoura@terra.com.br.

Nilton Roberto Kloeppel é mestre em ciências contábeis pela Universidade Regional de Blumenau (Furb). E-mail: niltonkloe@uol.com.br. 
